\title{
In vitro mass propagation of flowering plant Torenia (Torenia fournieri Lind.) through nodal segment
}

\author{
SAM Shariar Islam ${ }^{1}$, MH Kabir ${ }^{1}$, Pronabananda Das ${ }^{1}$, Md. Monirul Islam 1, 2, ${ }^{*}$, Md Monirul Islam ${ }^{1}$, MR Islam ${ }^{1}$, MT \\ Jahan ${ }^{1}$, MAH Bhuiyan ${ }^{3}$, MT Islam ${ }^{4}$ and ANK Mamun ${ }^{1}$ \\ ${ }_{1}^{1}$ Plant Biotechnology and Genetic Engineering Division, Institute of Food and Radiation Biology, Bangladesh Atomic Energy \\ Commission, Dhaka, Bangladesh. \\ ${ }^{2}$ United Graduate School of Agriculture, Tokyo University of Agriculture and Technology, Tokyo, Japan. \\ ${ }^{3}$ Department of Botany, University of Dhaka, Dhaka -1000, Bangladesh. \\ ${ }^{4}$ Gamma Source Division (GSD), Institute of Food and Radiation Biology, Bangladesh Atomic Energy Commission, Dhaka, \\ Bangladesh.
}

GSC Biological and Pharmaceutical Sciences, 2022, 18(01), 153-159

Publication history: Received on 13 December 2021; revised on 27 January 2022; accepted on 29 January 2022

Article DOI: https://doi.org/10.30574/gscbps.2022.18.1.0032

\begin{abstract}
Torenia fournieri is an important ornamental plant in Bangladesh that can grow in a variety of soils in moist areas. It is an extensively studied plant species to investigate fertilization and movement of chromosome. This investigation was carried out to establish a suitable protocol for large scale in vitro regeneration. In vitro mass propagation is one of the best biotechnological methods that can be ensured rapid multiplication of disease-free propagules and genetically identical plant production for plant breeding. In vitro plant regeneration in Torenia was obtained on MS medium supplemented with $2.0 \mathrm{mg} / \mathrm{l} \mathrm{BA}$ using nodal segments as explants. Maximum $95 \%$ of the explants were produced multiple shoots in this medium. The maximum number (12) of shoot per explant and the maximum shoot length of 5.5 $\mathrm{cm}$ were observed after 60 days of culture. The well-rooted were found when strong and healthy shoots were transferred into half strength of MS+ $1.0 \mathrm{mg} / \mathrm{l}$ IBA. The maximum number (18) of root per shoot and the maximum root length of $4.83 \mathrm{~cm}$ were recorded in this medium after 30 days of culture whilst $90 \%$ of shoots induced root. In vitro raised plantlets did not show any morphological variation and $90 \%$ of plantlets was survived in the natural environment. In this study, rapid multiplication of planting material in Torenia through in vitro propagation techniques such as shoot initiation, multiplication, rooting, hardening and optimizing the concentrations and combinations of plant growth regulators is developed. This regeneration protocol will be helpful in in vitro mutagenesis technique to create new variation of this plant within short time cycle.
\end{abstract}

Keywords: In vitro regeneration; Nodal segments; Torenia fournieri; Mass propagation

\section{Introduction}

Torenia fournieri is commonly known as wishbone flower or the bluewings. It has a different colours of flower like pink, blue or white with a yellow marking. The white coloured one also called as white moon Torenia. It is an important ornamental plant in Bangladesh. The genus of Torenia belongs to Scrophulariaceae family which was found in tropical Asia and Africa. This genus includes about 50 species and all of them are perennial herbs that can grow in moist areas with partial sunlight. Most of the species are cultivated in Cambodia, Laos, Vietnam and Thailand (Yamazaki, 1985). Torenia fournieri, the most ploughed species in the world, is usually seen in the homestead, offices and along the highways for beautifying the environment with improved environmental protection and also to promote living quality

\footnotetext{
${ }^{*}$ Corresponding author: Md. Monirul Islam

Plant Biotechnology and Genetic Engineering Division, Institute of Food and Radiation Biology, Bangladesh Atomic Energy Commission, Dhaka, Bangladesh.
} 
and healthy body. It is used as a model plant to study fertilization and movement of chromosomes (Kikuchi et al., 2005). Torenia is propagated by seeds and planted at the start of the rainy season. But seed germination is limited due to the seed dormancy and other agronomic factors. On the other hand, vegetative propagation is not successful due to the disease and insect prone propagules. Plant tissue culture method is an attractive alternative approach to overcome those limitations. Plant cell or tissue cultured in vitro is capable of regenerating whole plants. Biotechnology affords a novel method for mass propagation (Murashige, 1977) with clonal uniformity (Iqbal et al., 2003). Tissue culture method can be used to produce high-quality vegetative planting material, which ensures productivity and disease-free plantlets. In-vitro culture technique is an alternative and appropriate means to produce propagules without seasonal barrier, increase multiplication rates and also produce high yielding varieties, disease-free and resistant planting materials even from infected mother plants (Acedo, 2006). In vitro propagation can be used to create a cultivar that retains its unique qualities when bred with the same cultivar planting materials. In-vitro propagation can be carried out regardless of the growing season, enable the year-round availability of planting materials and ensure the expansion of production. Mutation breeding is an essential technique to produce variation in any plants. And to start working on mutation breeding or genetic transformation, a successful regeneration protocol is a prerequisite. Given these, a high frequency propagation system of Torenia is required. Few reports are available which uses tissue culture techniques for micropropagation (Tanimoto and Harada, 1986; Kobayashi et al., 1995) and genetic transformation in Torenia fournieri (Aida et al., 2000; Li et al., 2006; Li et al., 2007). It has been also reported that the stem segment of Torenia fournieri can regenerate adventitious buds and axillary shoots in in vitro propagation (Ishioka and Tanimoto, 1992). Plants regenerated from nodal segments are seen to be one of the most promising methods for propagating a specific variety that is true to type (Alam et al., 2015). But no reports of shoot regeneration from nodal segments have been made in the case of Torenia. So, this study is conducted using in vitro culture technique and nodal segments as explants which treated with different media components to produce a commercial scale true-to-type elite clone with disease-free and uniform quality. The objective of this study was to design an effective protocol for regenerating Torenia from nodal segments which will be very essential for new variety development using mutation breeding or genetic transformation.

\section{Material and methods}

\subsection{Plant material collection}

A high frequency in vitro regeneration protocol was established using nodal segments as explant. Young explants of Torenia fournieri (white-coloured) were collected from D.C nursery located in Savar, Dhaka. After collection, they were planted and conserved in the experimental garden in the natural environment for explants source during June 2020. This study was taken place in the experimental field of Plant Biotechnology and Genetic Engineering Division, Institute of Food and Radiation Biology, Bangladesh Atomic Energy Commission, Dhaka, Bangladesh.

\subsection{Surface sterilization of Explants}

First of all, explants were washed thoroughly with the detergent Trix and kept for 20 minutes under running tap water to eliminate dirt and organisms. From the explants source, nodes were collected and excised into $3.00 \mathrm{~cm}$ segments and put in a sterile conical flask for surface sterilization. The nodes were surface sterilized in a laminar airflow cabinet by sinking in an aqueous solution of $0.1 \%$ mercuric chloride accompanied with 2 drops of 'tween 20 ' for 10 minutes under aseptic conditions. The sterilized nodes were washed with sterile distilled water 6 times. After surface sterilization, the nodes were placed on the sterile Petri dish using sterile forceps.

\subsection{In vitro growth condition and nutrient medium}

The nodes were placed on MS basal medium with different concentrations and combinations of plant growth regulators (BA, NAA) for multiple shoot induction (Murashige and Skoog 1962). For healthy multiple shoots, Subculture was done at 30 days intervals on the same media. For induction of roots, healthy shoots were transferred to $1 / 2$ strength of MS media supplemented with various concentrations of IBA $(0.5 \mathrm{mg} / \mathrm{l}$ to $2.0 \mathrm{mg} / \mathrm{l})$, IAA (0.5 mg/l to $2.0 \mathrm{mg} / \mathrm{l})$ and NAA (0.5 $\mathrm{mg} / \mathrm{l}$ to $2.0 \mathrm{mg} / \mathrm{l}$ ). MS media containing standard salts and vitamins, $3 \%$ sucrose and $0.8 \%$ agar were used and $\mathrm{PH}^{\mathrm{H}}$ of the media adjusted to 5.8 previously autoclaving at $1.05 \mathrm{~kg} / \mathrm{cm}^{2}$ pressure, and $121^{\circ} \mathrm{C}$ for 20 minutes. Cultures were incubated at $25 \pm 2{ }^{\circ} \mathrm{C}$ with 16/8 hours light/dark cycle provided by cool white fluorescent tubes. In the in vitro condition, the regenerated plantlets were prepared to be taken to the soil after rooting.

\subsection{Acclimatization}

Healthy rooted plantlets were carefully transferred from the culture vessels and agar attached to the root was removed by gentle washing under running tap water. Then, the plantlets were shifted to pots containing a mixture of soil and 
compost in a 2:1 ratio. The pots were kept in a shady place and a few days later, plantlets were transferred to the large pots. By this time the plantlets were consecutively acclimatized to ex-vitro conditions.

\subsection{Statistical Analysis}

The experiments were set in a completely randomized design with three replications for each treatment and 30 explants per replication. The data pertaining to the number of inoculated explant responses, number of multiple shoots per plant, length of shoots per micro shoot and rooting were subjected to analysis of variance (ANOVA) test. Duncan's Multiple Range Test (DMRT) $(\mathrm{P}<0.05)$ using STAR program was used to analyze the huge data.

\section{Results}

Nodal segments of Torenia were cultured on MS basal media supplemented with different concentrations and combinations of plant growth regulators. The effect of various concentrations and combinations of plant growth regulators were observed to optimize the media components for maximum shoot proliferation. The cultured nodal segments enlarged and became a clump of adventitious shoots within 2 weeks (fig.1.c). But there was a significant difference in shoot number due to the use of different media components (Table- 1 ).

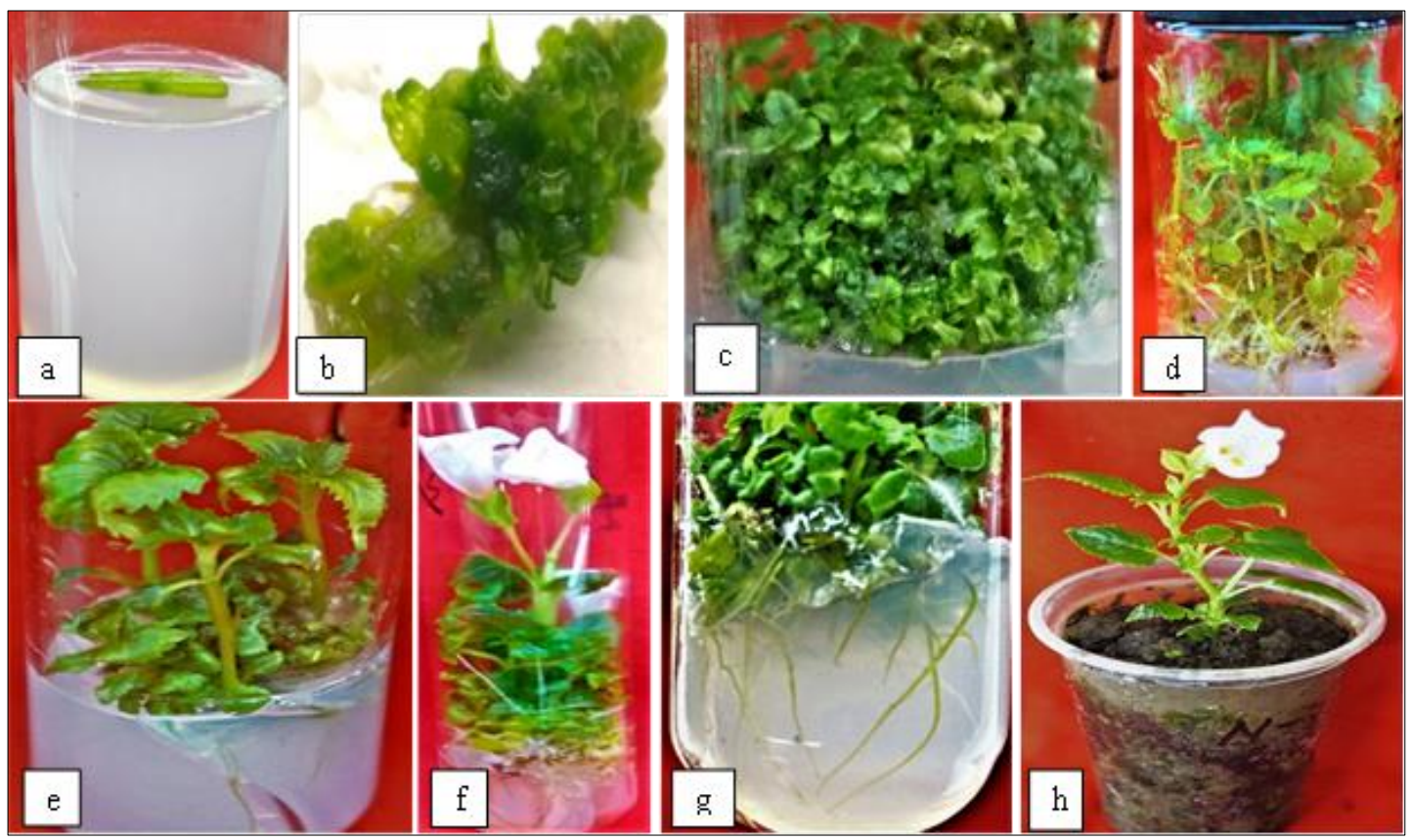

Figure 1 In vitro regeneration of Torenia spp. a) inoculation of nodal segments on MS medium supplemented with 2 $\mathrm{mg} / \mathrm{l} \mathrm{BA}(\mathrm{b})$ explant responded to the same medium (c) multiple shoot bud initiatiation on the same medium (d) elongation and multiplication of shoots on MS medium with $2 \mathrm{mg} / \mathrm{l} \mathrm{BA}$. (e) elongated shoots of Torenia (f) in vitro flowering in the test tube on MS medium (g) rooting of the excised shoots on 1/2 MS medium containing 1 mg/l IBA (h) Plantlets transplanted and acclimatized in small glass pot.

Among these media concentrations and combinations, the highest percentage (95\%) of explants responded and the maximum (12) number of shoot/explants were found at MS+2.0 mg/l BA for shoot proliferation and multiplication. The highest $(5.55 \mathrm{~cm})$ shoot length was also found in the same media after 60 days of cultured explants (Table-1). Among the another set of media combination of BA and NAA, the highest percentage (87\%) of explants responded and the maximum (8) number of shoot/explants were found at MS+1.0 mg/l BA+0.5 mg/l NAA media. From the study, it was indicated that the combination of MS+2.0 mg/l BA showed the increasing trend of explant responding for shoot proliferation and the performance of shoot length compared to the combinations of MS +BA+NAA. 
Table 1 Effect of different concentrations and combinations of plant growth regulators on in vitro shoot induction of Torenia fournieri using nodal segments as explant inoculated after 60 days.

\begin{tabular}{|c|c|c|c|c|}
\hline \multicolumn{2}{|c|}{$\begin{array}{c}\text { Different } \\
\text { treatments } \\
\text { on MS media } \\
(\mathrm{mg} / \mathrm{l})\end{array}$} & \multirow[t]{2}{*}{$\begin{array}{c}\text { \% of explants induced } \\
\text { shoot }\end{array}$} & \multirow[t]{2}{*}{$\begin{array}{c}\text { Average number of shoot induced/ } \\
\text { explant }\end{array}$} & \multirow[t]{2}{*}{$\begin{array}{c}\text { Average } \\
\text { shoot } \\
\text { length }(\mathrm{cm})\end{array}$} \\
\hline $\mathrm{BA}$ & NAA & & & \\
\hline 1.00 & - & $72.00 \mathrm{~d}$ & $8.00 \mathrm{abc}$ & $4.42 \mathrm{bc}$ \\
\hline 2.00 & - & $95.00 \mathrm{a}$ & $12.00 \mathrm{a}$ & $5.55 \mathrm{a}$ \\
\hline 3.00 & - & $82.00 \mathrm{c}$ & $10.00 \mathrm{ab}$ & $4.09 \mathrm{bc}$ \\
\hline 4.00 & - & $89.00 \mathrm{~b}$ & $11.00 \mathrm{ab}$ & $3.64 c$ \\
\hline 1.00 & 0.5 & $87.00 \mathrm{~b}$ & 8.00abc & $4.39 \mathrm{bc}$ \\
\hline 2.00 & 1 & $82.00 \mathrm{c}$ & $7.00 \mathrm{bcd}$ & $3.56 \mathrm{c}$ \\
\hline 3.00 & 1.5 & $39.00 \mathrm{e}$ & $5.00 \mathrm{~cd}$ & $3.81 b c$ \\
\hline 4.00 & 2 & $29.00 \mathrm{f}$ & $3.00 \mathrm{~d}$ & $4.63 \mathrm{ab}$ \\
\hline \multicolumn{2}{|c|}{ CV\% } & 0.98 & 18.07 & 7.71 \\
\hline \multicolumn{2}{|c|}{ Average mean } & 71.88 & 8.00 & 4.26 \\
\hline
\end{tabular}

In a column, the figures with a similar letter (s) do not differ significantly by DMRT (Duncan's multiple ranges test) at $\mathrm{p}<0.05$ : CV: Coefficient of variation, ${ }^{* * *}=$ significant

The combination of higher concentrations of NAA with BA reduced the rate of shoot regeneration (87\% to $29 \%)$ compare to lower concentrations (Table-1). Clump of shoots from nodal segments were subcultured to MS medium with growth regulators for 30 days and extended leaves were found (fig.1.d). Strong and healthy shoots were transferred to different concentrations of IBA, IAA, and NAA with half strength of MS supplemented media for root induction. The roots were well found on almost every concentration of plant growth regulators.

Table 2 Effect of IBA, IAA and NAA on half strength of MS media in root induction of in vitro raised shoots of Torenia fournieri after 30 days.

\begin{tabular}{|l|c|c|c|c|c|c|c|c|c|}
\hline \multirow{2}{*}{$\begin{array}{c}\text { Different } \\
\text { treatments on 1/2 } \\
\text { MS media (mg/I) }\end{array}$} & \multicolumn{3}{c|}{$\begin{array}{c}\text { \% of shoot } \\
\text { induced roots }\end{array}$} & \multicolumn{2}{c|}{$\begin{array}{c}\text { Average number of } \\
\text { root induced/ shoot }\end{array}$} & \multicolumn{4}{c|}{$\begin{array}{c}\text { Average root length } \\
\text { (cm) }\end{array}$} \\
\cline { 2 - 13 }$y$ & IBA & IAA & NAA & IBA & IAA & NAA & IBA & IAA & NAA \\
\hline 0.5 & $50.00 \mathrm{~b}$ & $36.00 \mathrm{c}$ & $43.00 \mathrm{c}$ & $7.00 \mathrm{~b}$ & $7.67 \mathrm{~b}$ & $7.00 \mathrm{c}$ & $3.70 \mathrm{~b}$ & $3.42 \mathrm{~b}$ & $3.57 \mathrm{a}$ \\
\hline 1.0 & $90.00 \mathrm{a}$ & $36.67 \mathrm{c}$ & $57.67 \mathrm{~b}$ & $18.00 \mathrm{a}$ & $7.00 \mathrm{~b}$ & $10.00 \mathrm{~b}$ & $4.83 \mathrm{a}$ & $3.00 \mathrm{c}$ & $3.33 \mathrm{~b}$ \\
\hline 1.5 & $63.33 \mathrm{ab}$ & $46.00 \mathrm{~b}$ & $66.67 \mathrm{a}$ & $11.00 \mathrm{~b}$ & $6.00 \mathrm{c}$ & $12.33 \mathrm{a}$ & $3.47 \mathrm{bc}$ & $3.17 \mathrm{c}$ & $3.00 \mathrm{c}$ \\
\hline 2.0 & $52.00 \mathrm{~b}$ & $54.00 \mathrm{a}$ & $62.67 \mathrm{a}$ & $8.00 \mathrm{~b}$ & $9.00 \mathrm{a}$ & $10.00 \mathrm{~b}$ & $3.03 \mathrm{c}$ & $3.68 \mathrm{a}$ & $3.55 \mathrm{a}$ \\
\hline CV\% & 21.17 & 4.78 & 3.65 & 18.74 & 19.46 & 8.30 & 7.03 & 9.91 & 17.84 \\
\hline Average mean & 63.83 & 43.17 & 57.50 & 11 & 7.42 & 9.83 & 3.76 & 3.32 & 3.36 \\
\hline
\end{tabular}

In a column, the figures with a similar letter (s) do not differ significantly by DMRT (Duncan's multiple ranges test) at p<0.05: CV: Coefficient of variation, $* * *=$ significant

The highest percentage (90\%) of roots was induced at $1.0 \mathrm{mg} / \mathrm{l}$ IBA supplemented with half strength of MS media. The maximum number (18) of roots per shoot and the maximum root length of $4.83 \mathrm{~cm}$ were found in this medium after 30 days of culture (Table-2). On the other hand, the other medium explants had a comparatively poor reaction. The roots sprouted from the basal end of shoots which was large and vigorous and efficient for acclimatization (fig.1.g). When the concentration of IAA and NAA was increased individually, the percentage of root regeneration gradually increased from $36 \%$ to $54 \%$ and $43 \%$ to $66 \%$ respectively (Table-2). After hardening, ninety percent (90\%) of plantlets were survived at the ex-vitro condition. During the in vitro culture, the plants sprouted from the nodal segment did not show any morphological changes as compared to the mother plant. 


\section{Discussion}

The aim of the present investigation was to develop an efficient in vitro regeneration protocol for large scale production of plantlets using nodal segments as explant of Torenia fournieri. The present study was showed that BA supplemented with MS media performed best in terms of explants responding for shooting, average number of shoot production and the performance of average shoot length induction. A similar result was also found in Cassava for shoot initiation and multiplication (Pita et al., 2001; Onuoch and Onwubiku, 2007; Guohua, 1998; Roca, 1984; Trigiano and Gray, 2000; Roca, 1980). The different concentrations of BA with NAA were found to have synergistic effect for shoot induction. Similar effects of BA supplemented with NAA was also found in other ornamental plants such as Tagetes (Kothari and Chandra, 1984; Belarmino et al., 1992) Lilium (Liu and Burger, 1986) and Dianthus (Jethwani and Kothari, 1993). The higher concentrations of NAA with BA showed the decreased trend of explants responding for shooting, average number of shoot induction compared to the BA supplemented with MS media (Table-1).

A similar result was found in plant regeneration of Torenia fournieri through micropropagation in shoot regeneration from the leaf explants (Kantamaht et al., 2009). But the combination of lower concentrations of NAA with BA increased the rate of shoot regeneration, average number of shoot induction and the performance of average shoot length compared to higher concentrations. When only the concentration of BA was increased, the shoot length was comparatively decreased. It indicated that, the concentrations and combinations of the plant growth regulators had a significant impact on plant micropropagation. Many authors (Roy et al., 2011; Roy and Kabir, 2006) reported that combination of two plant growth regulators showed better result for shoot multiplication and proliferation but in this study, single plant growth regulator showed the best result for shooting, average number of shoot production and the performance of average shoot length induction compared to combination of two plant growth regulators [Table-1]. Our results reveal that, the combination of BA supplemented with MS media performed excellent for shoot proliferation and shoot multiplication which was also supported (Aggarwal and Barnak, 2004). The rooting response varied depending on the auxins concentration used in the study. Among the auxins used, IBA was shown to be the best for shoot responding rooting, average number of roots induced per shoot and the performance of average root length induction. It has been reported that the IBA is superior over other auxins (Amin et al., 1992). It has been also reported that the IBA is superior to IAA and NAA for rooting of many other in vitro raised plants (Roy and Kabir, 2007). The percentage (90\%) of root induction was the best found at $1.0 \mathrm{mg} / \mathrm{l}$ IBA. A similar result also found in Gladiolus for root induction (Kabir et al., 2014). When the concentration of IBA was increased, the percentage of root induction decreased significantly which was also reported earlier (Kabir et al., 2014). This study reveals that, a high concentration of IBA was less effective for rooting or incompetent media type that inhibited the root induction of Torenia fournieri. But when the concentration of IAA and NAA was increased, root induction, average number of root and the root length increased consecutively. It indicates that root induction potential varies with the different concentrations of plant growth regulators due to the effect of genotypes of the studied plant.

\section{Abbreviations}

BA: Benzyl adenine;

IAA: Indole-3-acetic acid;

NAA: 1- Naphthaleneacetic acid;

IBA: Indole-3-butyric acid;

MS: Murashige and Skoog medium.

\section{Conclusion}

In vitro plant regeneration system was successfully developed for Torenia fournieri using nodal segments as explants. Therefore, the protocol was established in this study which will be useful for conservation, commercial cultivation, providing disease-free quality planting materials and necessity in developing new variety using irradiation of this ornamental plant.

\section{Compliance with ethical standards}

\section{Acknowledgments}

I expressed my gratitude to D.C nursery for providing the young plant of Torenia and my thanks also go to the technicians and colleagues who helped with the lab work, data collection and analysis. 


\section{Disclosure of conflict of interest}

No potential conflict of interest was reported by the author(s).

\section{Author's contributions}

SAM Shariar Islam carried out the study design, literature citing, creation of figures and tables and also manuscript writing. MH Kabir, P Das, and Md Monirul Islam helped to conduct literature citing, table and figure formation and manuscript writing. MR Islam, MT Jahan and MT Islam contributed to manuscript reading and literature citing. MAH Bhuiyan participated in helping edit, revise the manuscript. ANK Mamun supervised the writing of the manuscript and revised it critically for important intellectual content. All authors read and approved the final manuscript.

\section{References}

[1] Acedo VZ. Improvement of in vitro techniques for rapid meristem development and mass propagation of Philippine Cassava (Manihot Esculenta Crantz). J. Food. Agric. Env. 2006; 4(1): 220-224.

[2] Aida R, Kishimoto S, Tanaka Y, Shibata M. Modification of flower color in Torenia by genetic transformation. Plan. Sci. 2000; 153: 33-42.

[3] Aggarwal D, Barna KS. Tissue culture propagation of elite plant of Aloe vera Linn. J. Biochem. Biotech. 2004; 13: 77-79.

[4] Amin MN, Razzaque MA, Akhter S. Axillary shoot proliferation and adventitious rooting in vitro of carambola (Averrhoa carambola L.), Plan. Tiss. Cul. 1992; 2: 7-13.

[5] Alam MF, Amin R, Uddin ME, Biswas SK, Islam MM. Regeneration of shoot from nodal explants of Cucumis sativus considering different hormonal concentration. Int. Res. J. Bio. Sci. 2015; 4 (7): 48-52.

[6] Belarmino MM, Abe T, Sasahara T. Callus in-duction and plant regeneration in African marigold (Tagetes erecta L.). Jap. J. Breed. 1992; 42: 835-841.

[7] Guohua MA. Effects of cytokinins and auxins on Cassava shoot organogenesis and somatic embryogenesis from somatic embryo explants. Plan. Cell. Tiss. Org. Cul. 1998; 54: 1-7.

[8] Iqbal MJ, Khan MM, Fatima B, Asif M, Abbas M. In vitro propagation of hybrid tea roses. Pak. J. Agric. Sci. 2003; 40: 155-63.

[9] Ishioka N, Tanimoto S. Adventitious bud induction by protein kinase c activators in Torenia stem segments. Plan. Tiss. Cul. Lett. 1992; 9: 86-89.

[10] Jethwani V, Kothari SL. Micropropagation of Dianthus barbatus and D. chinensis through cotyle-done node culture. Plan. Tiss. Cul. 1993; 3: 91-96.

[11] Kabir MH, Mamun ANK, Talukder SU, Subramaniam S. In vitro clonal propagation of locally cultivated pink color Gladiolus var. Neelima through Cormel-sprout culture, Curre. Bot. 2014; 5:34-38.

[12] Kabir MH, Mamun ANK, Roy PK, Islam MR, Jahan MT, Talukder SU. In vitro mass propagation of Salvia (Salvia splendens) from nodal explant, Nuc. Sci. App. 2014; 23: $1 \& 2$.

[13] Kantamaht K, Nirunya B, Kamnoon K. Micropropagation through adventitious shoot regeneration from leaf culture of Torenia fournieri. Songklanakarin J. Sci. Technol. 2009; 31(6): 587-590.

[14] Kikuchi S, Shimizu M, Tsujimoto H. Centromere-specific repetitive sequences from Torenia, a model plant for interspecific fertilization and whole-mount FISH of its interspecific hybrid embryos. Cyto. gen. Res. 2005; 109: 228-235.

[15] Kobayashi S, Amaki W, Higuchi H. Effects of medium pH on shoot growth and flowering of Torenia inter nodal stem segments in vitro. Act. Hort. 1995; 393: 135-142.

[16] Kothari SL, Chandra N. Plant regeneration from Culture Disc florets of Tagetes erecta L. J. Plan. Physiol. 1984; 117(2): 105-108.

[17] Li ML, Wang XJ, Li HQ. Establishment of Agrobacterium-mediated transformation system for Torenia. Act. Hort. Sinica. 2006; 33: 105-110.

[18] Li HQ, Kang PJ, Li ML, M. R. Li MR. Genetic transformation of Torenia fournieri using the PMI/mannose selection system. Plan. Cell. Tiss. Org. Cul. 2007; 90: 103-109. 
[19] Liu L, Burger DW. In vitro propagation of Easter lily from pedicels, Hort. Sci. 1986; 21: 1437-1438.

[20] Murashige T. Plant cell and organ culture as horticultural practices. Act. Hort. 1977; 78: 17-30.

[21] Murashige T, Skoog F. A revised medium for rapid growth and bioassay with tobacco tissue cultures. Physiol. Plan. 1962; 15: 473-497.

[22] Onuoch CI, Onwubiku NIC. Micropropagation of Cassava (Manihot Esculantum Crantz.) using different concentrations of benzyaminopurin. J. Eng. Appl. Sci. 2007; 2: 1229-1231.

[23] Pita JS, Fondong VN, Sanggare A, Kokora RNNN, Fauquet CM. Genomic and Biological Diversity of the African Cassava Gemini viruses, Euphyt. 2001; 120: 115-125.

[24] Roca WM. EI Cultivo de Meristemas de Yuca. Guia de Estudio, Centro Internacional de Agri. Trop. Colom. 1980; 1-40.

[25] Roca WM. Cassava, In Handbook Plan. Cell. Cul. (eds. Sharp WR, Evans DA, Ammirato P and Yamada Y), New York, Macmillan. Crop. Spec. 1984; 2: 269-301.

[26] Roy PK, Mamun ANK, Kabir MH, Islam MR, Jahan MT, Rahman MZ. Large scale propagation of Ananas comosus (L) var. honey queen through in vitro culture of crown tip explants. Bang. J. Life. Sci. 2011; 23: 71-8.

[27] Roy PK, Kabir MH. In vitro propagation of sweet orange (Citrus sinensis) through plumule and cotyledon culture. Bang. J. Life. Sci. 2006; 18: 107-12.

[28] Roy PK, Kabir MH. In vitro mass propagation of sugarcane (Saccharum officinarum L.) var. Isd 32 through shoot tips and folded leaves culture, Biotech. 2007; 6(4): 588-592.

[29] Tanimoto S, Harada H. Involvement of calcium in adventitious bud initiation in Torenia stem segments. Plan. Cell. Physiol. 1986; 27 (1): 1-10.

[30] Trigiano RN, Gray DJ. Plan. Tiss. Cul. Conc. and Lab. Exer. CRC Pres. Wash. USA. 2000; 1: 454.

[31] Yamazaki T. A revision of the Genera Limnophila and Torenia from Indochina. J. Fac. Sci. Univ. Tokyo III. 1985; 13: 575-624. 